\title{
INVESTIGATION ON OXYGEN PERMEABILITY AND SURFACE PROPERTIES OF AGAR FILMS
}

\author{
Esam Abdulkader Elhefian*1,2, Sariah Saalah ${ }^{3}$ and Abdul Hamid Yahaya ${ }^{4}$ \\ ${ }^{1}$ Department of Chemistry, Faculty of Science, Sabratha University, Sabratha, Libya \\ ${ }^{2}$ Research, Consulting and Training Center, Sabratha University, Sabratha, Libya \\ ${ }^{3}$ Chemical Engineering Department, Faculty of Chemical and Natural Resources Engineering, \\ Universiti Teknologi Malaysia, 81310 UTM Skudai, Johor, Malaysia \\ ${ }^{4}$ Department of Chemistry, University of Malaya, 50603 Kuala Lumpur, Malaysia \\ eelhefian@yahoo.com
}

\begin{abstract}
In this work, agar (AG) films have been prepared using the cast method technique. Surface properties such as contact angle (CA) and morphology of the films were carried out. The water contact angle on the surface of agar film was recorded to be $74.91^{\circ} \pm 0.35$ indicating good hydrophilicity of the surface, which was confirmed by the scanning electron microscope (SEM) image of the AG film. The contact angle was also studied with the variation of time. After making the initial contact on the substrate, the water contact angle on the AG film was found to decrease gradually with time. Studying the oxygen permeability of the agar film showed that the film had an oxygen permeability of about 187 barer.
\end{abstract}

Keywords: permeability, properties, agar, film

\section{Introduction}

Agar, a gel forming polysaccharide, is a hydrophilic colloid extracted from the family of seaweeds (Rhodophycae) having a common backbone structure: 1,4linked- 3,6 -anhydro- $\alpha$-L-galactopyranose (Figure 1) (Araki et al, 1967). Agar is insoluble in cold water and slightly soluble in ethanolamine. However, it is soluble in hot water in the dried state (Phan et al, 2005). One of the most important properties of agar is its ability to form reversible gels even at low concentration simply by cooling its hot aqueous solutions. This is due to the formation of hydrogen bonds (Stephen et al, 1995; Glicksman, 1979; Armisen \& Galatas, 2000). This has given agar a wide use in a variety of industries including food industry products such as processed cheese, ice cream, bread and soft candy (Armisen, 1995; Freile-Pelegrín et al, 2007). 


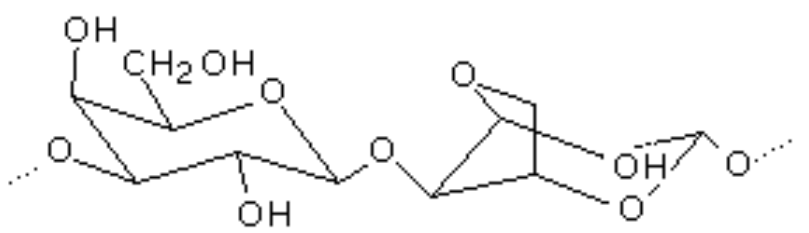

Figure 1: Original structure of agar repeat unit.

In this study, we report on an investigation of the oxygen permeability, contact angle and morphology of agar films with a view to further explore the properties of the agar thin film and films of its mixture with other selected polymers.

\section{Experimental part}

\section{Materials}

Agar was purchased from Sigma-Aldrich and its average molecular weight was 1.3 $\times 10^{4} \mathrm{~g} \mathrm{~mol}^{-1}$. All solutions were prepared using ultra pure water (Maxima Ultra Pure Water, Elga-Prima Corp, UK) with a resistivity greater than $18 \mathrm{M} \Omega / \mathrm{cm}$.

\section{Film Preparation}

Agar powder was dissolved in hot double-distilled water and stirred at temperature of $90^{\circ} \mathrm{C}$. After stirring for about 2 hours, the optically clear solution was obtained. 10 $\mathrm{mL}$ of the solution was then poured into polystyrene petri dish followed by drying at $60^{\circ} \mathrm{C}$ for $48 \mathrm{~h}$. The resultant films were peeled off gently and kept under evacuated desiccator over fresh silica gel until use. All obtained films were transparent and free of air bubbles. The flow diagram for preparation of agar films is summarized in Figure 2. 


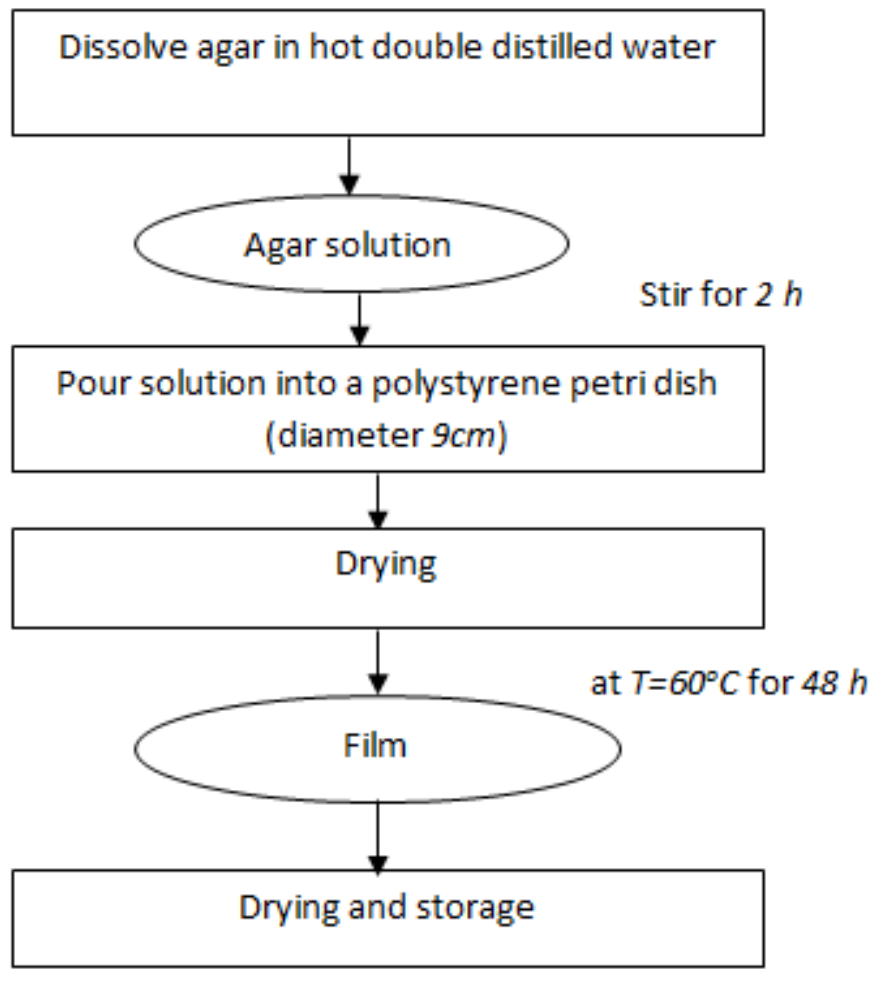

Figure 2: Flow diagram for preparation of agar films

\section{Film Thickness}

The film thickness was determined using a digital micrometer (Mitutoyo, Japan) with resolution of $0.001 \mathrm{~mm}$. Several thickness measurements were taken at several points of the film and then, the average was calculated. The thicknesses of the films were around $15 \mu \mathrm{m}$.

\section{FESEM Measurements}

Surface morphology was investigated by a FEI Quanta 200F field emission scanning electron microscope (FESEM) (FEI, USA) controlled by a 32 bit computer system using Microsoft Windows 2000 as an operating system.

\section{Contact angle measurements}

The static water contact angles of the films were measured at room temperature by the drop method using an optical contact angle meter CAM 200 (KSV Instruments Ltd, Helsinki, Finland) to examine the surface wettability of the films. The substrates used for the experiments were glass microscope slides $(25.4 \times 76.2 \mathrm{~mm}, 1-1.2 \mathrm{~mm}$ thick). Each slide was cleaned before use by soaking in ethanol overnight. $7 \mu \mathrm{L}$ of distilled water was carefully injected on the film surface before measuring. The contact angles were measured on both sides of the drop and averaged. The reported contact angle was the mean value of at least 10 measurements. 


\section{Gas Permeation Test}

Permeation test was conducted for the agar films using a variable volume apparatus attached to a local design soap bubble flow meter as presented in Figure 3. The membrane films were cut into a rounded shape with a diameter of $5 \mathrm{~cm}$. Afterwards, it was mounted between the upper and lower parts of the cell, followed by clamping and sealing tightly with a rubber O-ring. The measurement was conducted at room temperature over a pressure of 1.0 and 3.0 bars. Oxygen gas at specific pressure was fed into the system. After the gas flow in the permeate side reached steady state, the volumetric gas permeation rates were recorded.

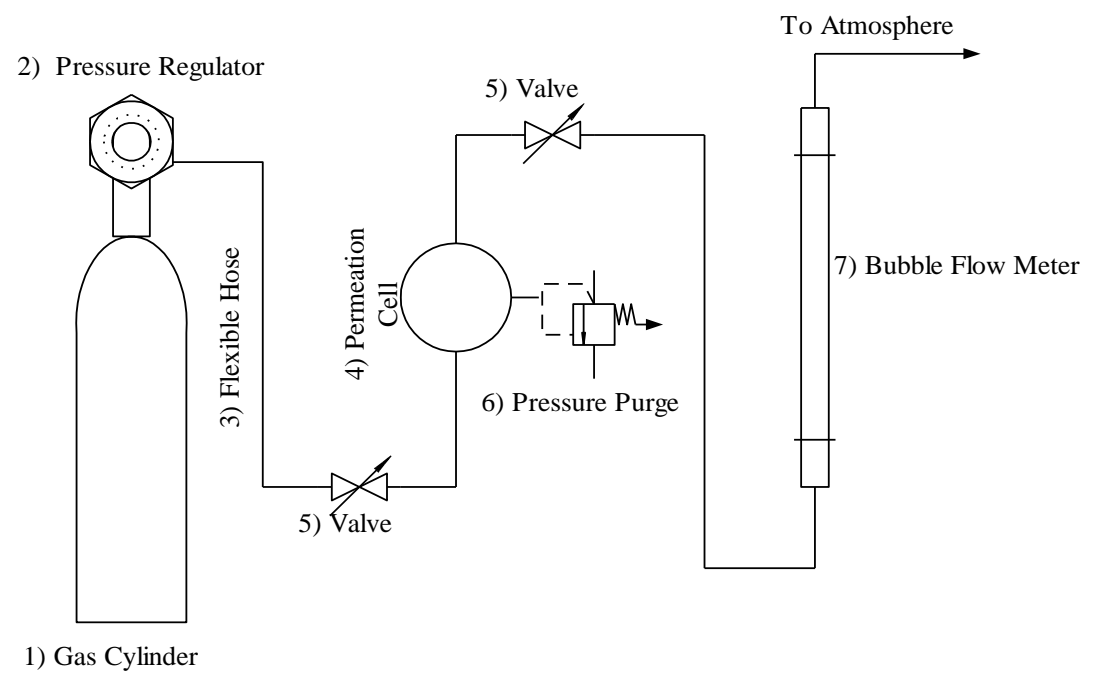

Figure 3: Schematic diagram of soap bubble flow meter used in this work

Pressure normalized fluxes, $(\mathrm{P} / \mathrm{L}) i$ of $\mathrm{O}_{2}$ were determined from bubble flow meter measurements by:

$$
\left(\frac{P}{L}\right)_{i}=\frac{Q_{i}}{(\Delta P)(A)}
$$

where $Q_{i}$ is volumetric flow rate of gas $i$ at standard temperature and pressure, $\Delta \mathrm{P}$ is the trans membrane pressure drop and $A$ is the membrane surface area.

Pressure - normalized gas fluxes are often reported in gas permeation units, GPU, where:

$$
G P U=1 \times 10^{-6} \mathrm{~cm}^{3}(\mathrm{STP}) / \mathrm{cm}^{2} \mathrm{scmHg}
$$




\section{Results and discussion}

\section{Oxygen permeability of agar hydrogel membrane}

Oxygen permeability of agar was successfully measured in this work to be 187 barrer. The data and detailed calculations for oxygen permeability are shown in Table 1.

Table 1: Pure $\mathrm{O}_{2}$ gas permeation results for pure agar.

\begin{tabular}{|c|c|c|c|c|c|c|c|c|c|}
\hline & $\begin{array}{c}\text { Trial } \\
\text { No. }\end{array}$ & $\begin{array}{c}\mathbf{T} \\
(\mathbf{s})\end{array}$ & $\begin{array}{c}\mathbf{V} \\
\left(\mathbf{c m}^{\mathbf{3}}\right)\end{array}$ & $\begin{array}{c}\mathbf{Q} \\
\left(\mathbf{c m}^{\mathbf{3}} / \mathbf{s}\right)\end{array}$ & $\mathbf{A}\left(\mathbf{c m}^{\mathbf{2}}\right)$ & $\begin{array}{c}\mathbf{L} \\
(\mathbf{c m})\end{array}$ & $\begin{array}{c}\square \mathbf{p} \\
(\mathbf{c m H g})\end{array}$ & $\begin{array}{c}\mathbf{P} \\
\left(\mathbf{c m}^{\mathbf{3}} \mathbf{. c m} / \mathbf{s . c m} \mathbf{2}\right. \\
\mathbf{c m H g})\end{array}$ & $\begin{array}{c}\mathbf{P} \\
(\mathbf{b a r r e r s})\end{array}$ \\
\hline \multirow{3}{*}{$\begin{array}{c}1 \\
\text { bar }\end{array}$} & 1 & 52 & 1.0 & 0.019231 & 13.26 & 0.0001 & 75 & $1.93371 \mathrm{E}-09$ & 193.3712 \\
& 2 & 55 & 1.0 & 0.018182 & 13.26 & 0.0001 & 75 & $1.82824 \mathrm{E}-09$ & 182.8237 \\
\cline { 2 - 10 } & Average & $\mathbf{5 3 . 6 7}$ & & $\mathbf{0 . 0 1 8 6 4 4}$ & $\mathbf{1 3 . 2 6}$ & $\mathbf{0 . 0 0 0 1}$ & $\mathbf{7 5}$ & $\mathbf{1 . 8 7 4 6 8 E - 0 9}$ & $\mathbf{1 8 7 . 4 6 8 1}$ \\
\hline \multirow{3}{*}{3} & 1 & 17 & 1.0 & 0.058824 & 13.26 & 0.0001 & 225 & $1.97163 \mathrm{E}-09$ & 197.1628 \\
bar & 2 & 20 & 1.0 & 0.05 & 13.26 & 0.0001 & 225 & $1.67588 \mathrm{E}-09$ & 167.5884 \\
\cline { 2 - 9 } & 3 & 17 & 1.0 & 0.058824 & 13.26 & 0.0001 & 225 & $1.97163 \mathrm{E}-09$ & 197.1628 \\
\hline & Average & $\mathbf{1 8 . 0 0}$ & $\mathbf{1}$ & $\mathbf{0 . 0 5 5 8 8 2}$ & $\mathbf{1 3 . 2 6}$ & $\mathbf{0 . 0 0 0 1}$ & $\mathbf{2 2 5}$ & $\mathbf{1 . 8 7 3 0 5 E}-\mathbf{0 9}$ & $\mathbf{1 8 7 . 3 0 4 7}$ \\
\hline
\end{tabular}

\section{Surface hydrophobicity and wettability}

The contact angle of the water droplet deposited into the surface of films is commonly used to describe their hydrophobicity/hydrophilicity, which is generally used to estimate the resistance of the film against liquid water (Phan et al, 2009; Rhim et al, 2006). Generally, the more hydrophilic a material is, the lower the CA value it has (Rhim et al, 2006). In this work, a contact angle of $74.91^{\circ} \pm 0.35$ was observed for the AG film, which is less than $90^{\circ}$, indicating good hydrophilicity of the surface. This was in agreement with the SEM image of the AG film, which showed a quite rough surface (Figure 4). The value of contact angle of AG film recorded in this work is lower than the one reported by Phan et al (2009) for agar based film $\left(92^{\circ}\right)$. This is acceptable since the source of agar and the thickness of this kind of films could have an effect on the contact angle measurement. The mapping and chemical analysis are shown in Figure 5 and summarized in Table 2.

Generally, the water droplet spreads out faster on soluble films surface than on surface of insoluble and swollen films. Since AG films are swollen, we expect a gradual spreading of the water droplet on its surface with time. Figure 6 shows the variation in the water contact angle with time for the AG film. The contact angle of 
the AG film decreases gradually after making the initial contact on the substrate due to the hydrophilic nature of AG. The change in contact angle with time could be due to evaporation and surface oxidation:dissolution (Raichur et al, 2000).
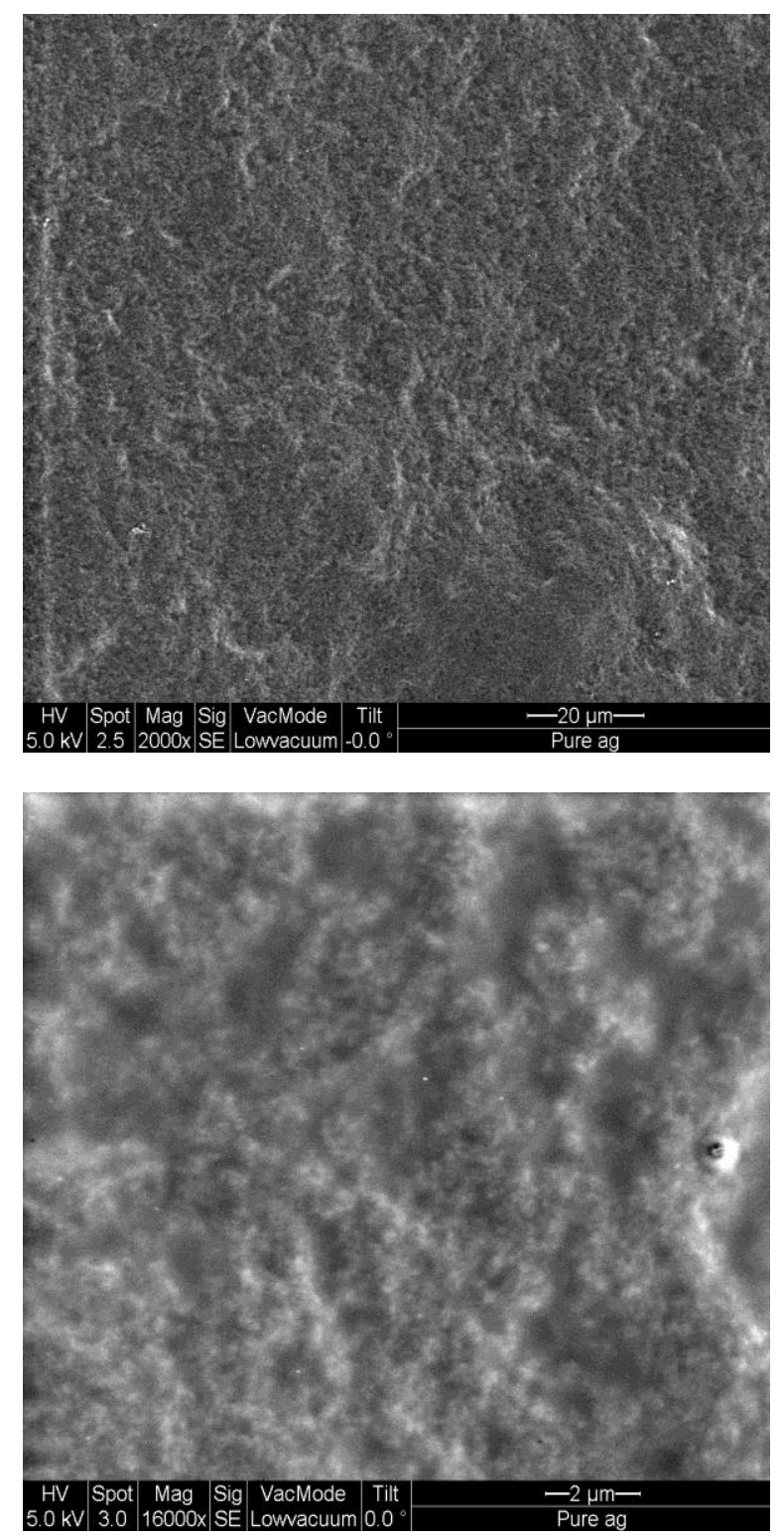

Figure 4: SEM micrographs of agar film (El-hefian et al, 2012). 


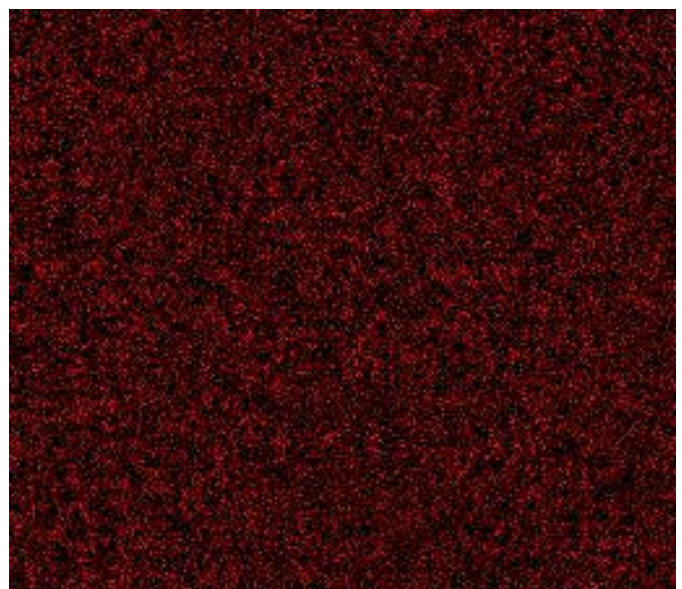

CKa1_2

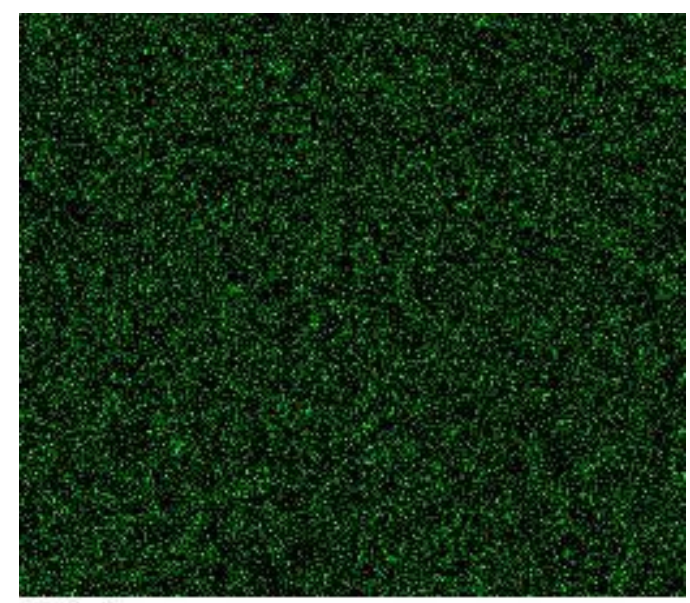

o Ka1

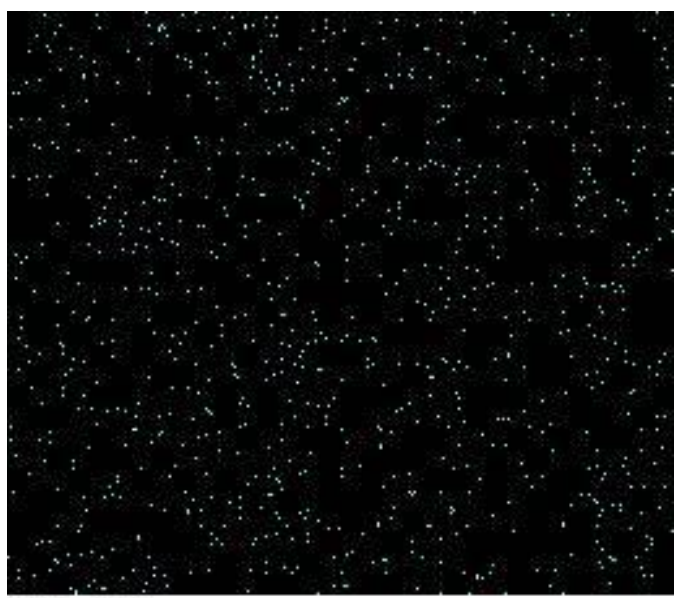

NKa1_2

Figure 5: Mapping analysis of agar film. 
Table 2: EDX (Energy Dispersive X-ray) analysis of agar film.

\begin{tabular}{|c|c|c|}
\hline Element & Weight\% & Atomic\% \\
\hline $\mathrm{C}$ & 43.02 & 49.57 \\
\hline $\mathrm{N}$ & 10.34 & 10.22 \\
\hline $\mathrm{O}$ & 46.13 & 39.91 \\
\hline $\mathrm{Na}$ & 0.51 & 0.31 \\
\hline Totals & 100.00 & \\
\hline
\end{tabular}

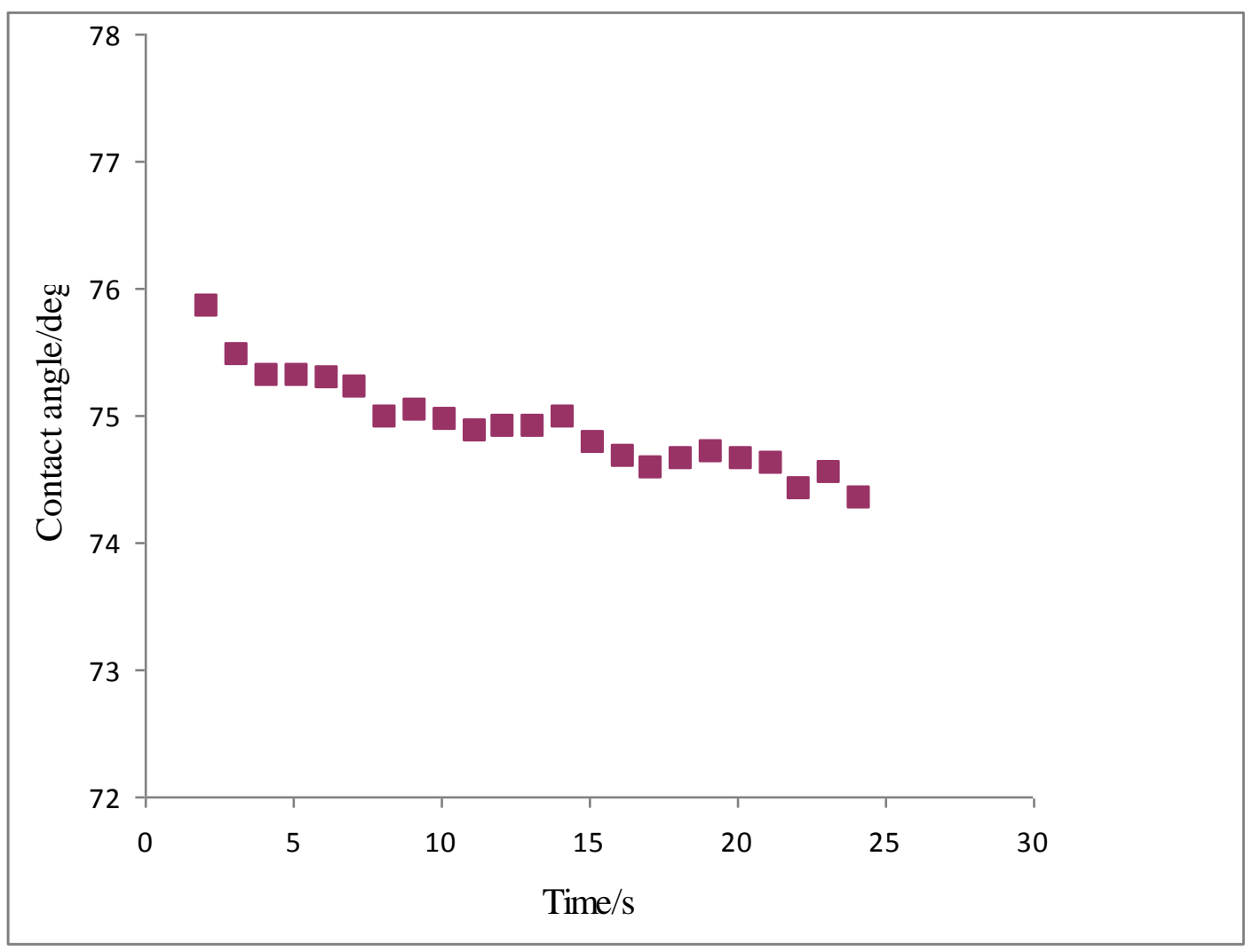

Figure 6: Variation of water contact angle on agar film with time.

\section{Conclusion}

This work has shown good hydrophilicity of agar films as indicated by surface properties i.e., contact angle and morphology. Water contact angle on the surface of agar film was found to be $74.91^{\circ} \pm 0.35$. The contact angle was also studied as a function of time. After making the initial contact on the substrate, the water contact angle on the AG film decreased gradually with time. On the other hand, oxygen permeability of agar film was determined to be 187 barrer using the bubble soup flow meter method. 


\section{References}

- Araki C, Arai K and Hirase S. (1967). Studies on the chemical constitution of agaragar.

- XXIII. Isolation of D-xilose, 6-Omethyl-D-galactose, 4-O-methyl-L-galactose and Omethylpentose. Bull. Chem. Soc. Japan. 40, 959-962.

- Armisen R. (1995). World-wide use and importance of Gracilaria. J Appl Phycol. 7, 231-243.

- Armisen R and Galatas F, Agar, in Philips G O and Williams P A (Eds.) (2000). Handbook of hydrocolloids; CRC Press: New York, 21.

- El-hefian E, Nasef M and Yahaya A (2012). Preparation and characterization of chitosan/agar blended films: Part 1. Chemical structure and morphology. E- Journal of Chemistry. 9(3): 1431-1439.

- Freile-Pelegrín Y, Madera-Santana T, Robledo D, Veleva L, Quintana P and Azamar J. A. (2007). Degradation of agar films in a humid tropical climate: Thermal, mechanical, morphological and structural changes. Poly. Degrad. Stab. 92, 244-252.

- Glicksman M. (1979). Gelling hydrocolloids in product applications, in: J. M. V. Blanshard, J. R. Mitchell (Eds), Polysaccharides in foods, Butterworths, London, 185-204.

- Phan T D, Debeaufort F, Luu D and Voilley A. (2005). Functional properties of edible agar-based and starch-based films for food quality preservation. J. Agric. Food Chem. 53, 973-981.

- Phan The D, Debeaufort F, Voilley A and Luu D. (2009). Biopolymer interactions affect the functional properties of edible films based on agar, cassava starch and arabinoxylan blends. J. Food Eng. 90, 548-558.

- Raichur A M, Wang X H and Parekh B K. (2000). Quantifying pyrite surface oxidation kinetics by contact angle measurements. Colloids Surf A Physicochem Eng Asp. 167, 245-251.

- Rhim J W, Hong S I, Park H M and Ng P K W. (2006). Preparation and characterization of chitosan-based nanocomposite films with antimicrobial activity. J. Agric. Food Chem. 54, 5814-5822.

- Stephen A M, Phillips G O and Williams P A. (1995). Food polysaccharides and their applications; Marcel Dekker Inc: New York, 187- 212. 